\title{
Estimating the Impact of Switching from a Lower to Higher Valent Pneumococcal Conjugate Vaccine in Colombia, Finland, and The Netherlands: A Cost- Effectiveness Analysis
}

\author{
Sarah Pugh (D) - Matt Wasserman · Margaret Moffatt - Susana Marques · Juan Manuel Reyes • \\ Victor A. Prieto · Davy Reijnders · Mark H. Rozenbaum · Juha Laine • Heidi Åhman • \\ Raymond Farkouh
}

Received: November 27, 2019 / Published online: February 24, 2020

(C) The Author(s) 2020

\section{ABSTRACT}

Introduction: Widespread use of ten-valent (Synflorix $^{\mathrm{TM}}$, GSK) or 13-valent (Prevenar $13^{\mathrm{TM}}$; Pfizer) conjugate vaccination programs has effectively reduced invasive pneumococcal disease (IPD) globally. However, IPD caused by serotypes not contained within the respective vaccines continues to increase, notably serotypes $3,6 \mathrm{~A}$, and $19 \mathrm{~A}$ in countries using lower-

Enhanced digital features To view enhanced digital features for this article go to https://doi.org/10.6084/ m9.figshare.11778303.

Electronic supplementary material The online version of this article (https://doi.org/10.1007/s40121020-00287-5) contains supplementary material, which is available to authorized users.

S. Pugh $(\bowtie) \cdot$ R. Farkouh

Pfizer Inc, Collegeville, PA, USA

e-mail: Sarah.Pugh@pfizer.com

M. Wasserman · M. Moffatt

Pfizer Inc, New York, NY, USA

S. Marques

Pfizer Inc, Lisbon, Portugal

J. M. Reyes - V. A. Prieto

Pfizer Inc, Bogotá, Colombia

D. Reijnders · M. H. Rozenbaum

Pfizer Inc, Capelle aan den IJssel, The Netherlands

J. Laine · H. Åhman

Pfizer Inc, Helsinki, Finland valent vaccines. Our objective was to estimate the clinical and economic benefit of replacing PCV10 with PCV13 in Colombia, Finland, and The Netherlands.

Methods: Country-specific databases, supplemented with published and unpublished data, informed the historical incidence of pneumococcal disease as well as direct and indirect medical costs. A decision-analytic forecasting model was applied, and both costs and outcomes were discounted. The observed invasive pneumococcal disease (IPD) trends from each country were used to forecast the future number of IPD cases given a PCV13 or PCV10 program. Results: Over a 5-year time horizon, a switch to a PCV13 program was estimated to reduce overall IPD among 0-2 year olds by an incremental $-37.6 \%$ in Colombia, $-32.9 \%$ in Finland, and $-26 \%$ in The Netherlands, respectively, over PCV10. Adults $>65$ years experienced a comparable incremental decrease in overall IPD in Colombia $(-32.2 \%)$, Finland $(-15 \%)$, and The Netherlands $(-3.7 \%)$. Serotypes 3,6A, and 19A drove the incremental decrease in disease for PCV13 over PCV10 in both age groups. A PCV13 program was dominant in Colombia and Finland and cost-effective in The Netherlands at $1 \times$ GDP per capita (€34,054/QALY).

Conclusion: In Colombia, Finland, and The Netherlands, countries with diverse epidemiologic and population distributions, switching from a PCV10 to PCV13 program would 
significantly reduce the burden of IPD in all three countries in as few as 5 years.

Keywords: Colombia; Cost-effectiveness; Finland; PCV10; PCV13; Pneumococcal conjugate vaccine; The Netherlands

\section{Key Summary Points}

\section{Why carry out this study?}

While the widespread use of higher-valent vaccines (PCV10 and PCV13) has successfully reduced pneumococcal disease, disease caused by serotypes not contained within the respective vaccines has still increased. Serotype replacement continues to be observed in all countries using PCVs, but evidence suggests higher replacement in countries using a lowervalent PCV, notably for serotypes 3 and 19A.

This is of particular importance as serotype $19 \mathrm{~A}$ is known for its link with more complicated disease, multidrug resistance and the need for longer antimicrobial treatment.

In the absence of head-to-head evaluations, recent studies propose utilizing the observed disease trends in a country, to date, to predict future disease incidence under each PCV10/PCV13 vaccine pressure. With impending decisions around immunization policies, this evidence is timely to inform decisionmakers.

Our objective was to estimate the clinical and economic benefit of replacing PCV10 with PCV13 in Colombia, Finland, and The Netherlands.

\section{What was learned from the study?}

A PCV13 program was dominant in Colombia and Finland and cost-effective in The Netherlands at $1 \times$ GDP per capita (€34,054/QALY).
In Colombia, Finland, and The

Netherlands, countries with diverse epidemiologic and population distributions, switching to a higher-valent PCV program would significantly reduce the burden of IPD in all three countries in as few as 5 years.

\section{BACKGROUND}

The bacterium Streptococcus pneumoniae (S. pneumoniae) can colonize the nasopharynx of healthy individuals and can spread to others or cause pneumococcal disease in the host. Diseases caused by the bacterium can be serious, resulting in meningitis and bacteremia/septicemia, or cause non-invasive mucosal infections, such as otitis media (OM) and pneumonia infections. The World Health Organization (WHO) estimated that pneumococcal infections caused $5.5 \%$ of global annual deaths among children $<5$ years of age in 2008 [1]. Both invasive and non-invasive pneumococcal disease presents a significant health and economic burden worldwide.

After the introduction of a seven-valent pneumococcal vaccine (PCV7, Prevenar ${ }^{\mathrm{TM}}$; Wyeth) into pediatric vaccination programs, the burden of pneumococcal diseases in both vaccinated and unvaccinated populations was substantially reduced worldwide [2-9]. However, despite the observed effectiveness of PCV7 against disease caused by the seven covered serotypes, serotypes not contained in the vaccine emerged to replace those reduced by vaccination [9-13]. This phenomenon, known as serotype replacement, occurs in the presence of reduced competition from vaccine-covered serotypes for the nasopharyngeal space, in which non-vaccine-type serotypes can either occupy space in asymptomatic individuals or progress to cause pneumococcal disease [14]. For example, in the UK and The Netherlands, from preto post-PCV7 vaccination, there was a $56-71 \%$ increase in non-vaccine-type disease among infants $<2$ years of age primarily due to 
serotype 19A, though net disease was still reduced by $44-48 \%[7,15]$.

To address the increase in non-vaccine-type disease, countries introduced next-generation conjugate vaccines containing a greater number of serotypes. Currently, countries with a pneumococcal national immunization program (NIP) have a program with either a ten-valent (PCV10, Synflorix ${ }^{\mathrm{TM}}$, GSK) or a 13-valent (PCV13, Prevenar $13^{\mathrm{TM}}$, Pfizer) vaccine. Both vaccines cover the following serotypes: $1,4,5$, 6B, 7F, 9V, 14, 18C, 19F, and 23F with PCV13 additionally covering 3,6A, and 19A (Supplementary Table 1 ). Widespread use of highervalent vaccines successfully reduced pneumococcal disease, though disease caused by serotypes not contained within the respective vaccines has still increased. While serotype replacement continues to be observed in all countries using PCVs, evidence suggests higher replacement in countries using PCV10 because of the lack of additional serotype coverage, notably for serotypes 3 and 19A. These serotypes have been increasing in countries such as Colombia, Finland and The Netherlands, which have utilized PCV10 for a number of years [16-18]. For example, in The Netherlands, in $2017 / 2018$ the incidence of IPD caused by serotypes $3,6 \mathrm{~A}$, and $19 \mathrm{~A}$ was $118 \%$ higher than before the introduction of PCV7 (2006) and $59 \%$ higher than before the introduction of PCV10 (2010) [19]. This is of particular importance as serotype 19A is known for its link with more complicated disease, multidrug resistance, and the need for longer antimicrobial treatment $[20,21]$. While serotype replacement also occurs in countries utilizing PCV13, the magnitude of replacement has been smaller and more varied [22-24]. Thus, implementing a higher-valent vaccine program in countries using PCV10 may mitigate the increasing disease due to nonPCV10 serotypes. However, no head-to-head controlled studies have compared the effectiveness of PCV10 versus PCV13 vaccination programs in the same epidemiologic setting; less is known about what impact a switch in vaccines would have on serotype replacement and clinical outcomes.

In the absence of head-to-head evaluations, recent studies propose utilizing the observed disease trends in a country, to date, to predict future disease incidence under each PCV10/ PCV13 vaccine pressure $[25,26]$. We hypothesize that switching to a higher-valent vaccine may yield considerable benefits, despite differences in country demographics, disease epidemiology, and vaccination coverage, all factors impacting serotype replacement. Colombia, Finland, and The Netherlands were selected to investigate these serotype dynamics as countries with diverse economic, geographical and social conditions and with varying vaccine introduction and serotype distribution across countries. Our objective was to apply this methodology to model serotype dynamics, forecast future disease under each PCV program, and calculate the costeffectiveness of switching to the higher-valent PCV in Colombia, Finland, and The Netherlands.

\section{METHODS}

\section{Model Design}

A decision-analytic forecasting model was developed to estimate the public health and economic impact of potential changes (e.g., reduction in vaccine-type disease, serotype reemergence) in incidence of pneumococcal disease in the event of a change in vaccination program. This model has been described in detail elsewhere [26]. To briefly summarize, this population-level model uses historical realworld surveillance data to forecast the change in serotype distribution and disease incidence over time across the entire population. All 13 serotypes contained within PCV13 and nonvaccine serotypes are separately modeled within seven age groups $(0-2,3-4,5-17,18-34,35-49$, $50-64$, and $65+$ years) based on historical surveillance data. Trends identified using these serotype- and age-specific historical data, when serotypes were or were not under vaccine pressure, are used to forecast future serotype behavior under either PCV10 or PCV13.

For each country under consideration, the model assesses the clinical and economic impact of continuing a PCV10 program compared with switching to a PCV13 infant vaccination program. In the current analysis, we 
evaluated the impact of such a change in Colombia, Finland, and The Netherlands, all of which utilize a $2+1$ vaccination schedule, and assumed a constant rate of $90 \%, 90 \%$, and $95 \%$ of infants were vaccinated, respectively, according to uptake estimates reported by the WHO. The remaining individuals comprise the non-vaccinated cohort. In the base case analysis, continuing use of PCV10 was forecasted based on the observed experience within that country. Because we assume that countries switching to a PCV13 vaccine would continue to follow a $2+1$ schedule, PCV13 was forecasted given the experience seen in the UK in the base case, a PCV13 country following a $2+1$ schedule. Given the country and serotype-specific forecasts, the number of cases of IPD, pneumococcal pneumonia (inpatient and outpatient), and pneumococcal OM are estimated over a 5-year time horizon. Rates of pneumococcal pneumonia and $\mathrm{OM}$ are calculated based on a proportion of all-cause disease incidence assumed to be caused by $S$. pneumoniae, and the rates of disease are assumed to change proportionally related to the same serotypes causing IPD, as has been done elsewhere in the literature $[27,28]$.

We also included an impact of PCVs against all (single-species and co-colonized episodes) non-typeable Haemophilus influenza (NTHi) and Moraxella catarrhalis OM. This assumption is based on recent studies indicating that PCV13 may have a broader impact on non-pneumococcal $\mathrm{OM}$ due to averting early onset cases, thereby averting later onset, more complex cases often caused by non-pneumococcal pathogens [29]. This was accomplished by applying an annual rate of change in disease for PCV13 of 0.755 (NTHi) ${ }^{1}$ and 0.759 (M. catarrhalis) against the residual OM caused by each pathogen. Due to more limited evidence on the impact of PCV10 against non-pneumococcal $\mathrm{OM}$, an annual rate of change in disease for PCV10 of 0.785 [30] (NTHi) and 0.0 (M. catarrhalis) was applied in sensitivity analyses [31]. In all three countries, NTHi and M. catarrhalis were estimated to cause $31.7 \%$ and $1.6 \%$ of OM disease, respectively [31]. The model inherently captures indirect effects (i.e., effects in those $>$ 5 years of age who are unvaccinated) for invasive disease, given the observed serotype trends include invasive disease behavior in both vaccinated and unvaccinated age groups.

Calculated costs and outcomes for the vaccination strategy included the number of disease cases and deaths avoided, of quality adjusted life years (QALYs) gained, and of total costs from a payer perspective. PCVs were considered cost-effective if they averted 1 quality adjusted life-year for less than three times per capita gross domestic product (GDP) and to be highly cost-effective at $<1$ times the GDP per capita in accordance with the WHO Commission on Macroeconomics and Health [32].

This article is based on previously conducted studies and does not contain any studies with human participants or animals performed by any of the authors. All data sets used in the analyses for Colombia and Finland were obtained from previously published sources or publicly available databases. Dr. Arie van der Ende from the Netherlands Reference Centre for Bacterial Meningitis (NRLBM) kindly provided IPD data for The Netherlands.

\section{Epidemiologic Setting and Inputs}

\section{Colombia}

Colombia first introduced a high-risk PCV7 program in 2006, which was replaced by a universal PCV10 program in 2012; both programs were implemented using a $2+1$ schedule (Table 1). Incidence data were derived from the Individual Registration of Health Services (RIPS) database, a health benefits information system from all health maintenance organizations that provide detailed data on historic and current disease. The RIPS database informed estimates for age-specific incidence of IPD from 2009 through 2015 [33] and was weighted based on individual serotype coverage from the SIREVA data set [34]. SIREVA is a pneumococcal serotype surveillance project covering 19 countries in Latin America for individuals > 14 years. We assumed that the serotype distribution was equivalent for all age groups $<18$ years. At the year of potential switch, the incidence of IPD in 0-2 year olds was 20.9 per 100,000 , of which serotype 19A (39\%), serotype 3 (13\%), and non- 
Table 1 Epidemiologic inputs used in the cost-effectiveness analysis of an infant pneumococcal vaccination program at time of switch

\begin{tabular}{|c|c|c|c|c|c|c|}
\hline Input & \multicolumn{2}{|l|}{ Colombia* } & \multicolumn{2}{|l|}{ Finland } & \multicolumn{2}{|c|}{ The Netherlands } \\
\hline \multicolumn{7}{|l|}{ PCV use, year } \\
\hline PCV7 & 2006 & & & & 2006 & \\
\hline PCV10 & 2012 & & 2010 & & 2011 & \\
\hline Modeled year at switch & 2016 & & 2016 & & 2015 & \\
\hline Vaccine uptake & $90 \%$ & & $90 \%$ & & $95 \%$ & \\
\hline Age-specific inputs & 0 to $<2$ years & $\geq 65$ years & 0 to $<2$ years & $\geq 65$ years & 0 to $<2$ years & $\geq 65$ years \\
\hline Total population & $1,747,273$ & $3,741,593$ & 111,290 & $1,136,539$ & 346,268 & $3,007,685$ \\
\hline \multicolumn{7}{|l|}{$\begin{array}{l}\text { Invasive pneumococcal } \\
\text { disease (IPD) }\end{array}$} \\
\hline $\begin{array}{l}\text { Incidence (per 100,000 } \\
\text { person-years) }\end{array}$ & 20.9 & 41.8 & 14.4 & 36.2 & 5.6 & 51.7 \\
\hline Case fatality rate (\%) & 35 & 33 & 1 & 20 & 7 & 40 \\
\hline $\begin{array}{l}\text { Hearing loss, } \\
\text { probability of (\%) }\end{array}$ & 13 & 13 & 12 & 12 & 0 & 0 \\
\hline $\begin{array}{l}\text { Epilepsy, probability of } \\
(\%)\end{array}$ & 7 & 7 & 16 & 16 & 0 & 0 \\
\hline \multicolumn{7}{|l|}{ Inpatient pneumonia } \\
\hline $\begin{array}{l}\text { Incidence (per 100,000 } \\
\text { person-years) }\end{array}$ & 1474 & 790 & 628 & 129 & 284 & 408 \\
\hline Case fatality rate (\%) & 3 & 11 & 12 & 20 & 0.3 & 13 \\
\hline \multicolumn{7}{|l|}{ Outpatient pneumonia } \\
\hline $\begin{array}{l}\text { Incidence (per 100,000 } \\
\text { person-years) }\end{array}$ & - & - & 419 & 86 & 1348 & 2083 \\
\hline \multicolumn{7}{|l|}{ Simple acute otitis media } \\
\hline $\begin{array}{l}\text { Incidence (per 100,000 } \\
\text { person-years) }\end{array}$ & 3236 & & 90,327 & & 10,653 & \\
\hline Due to NTHi (\%) & 31.7 & & 31.7 & & 31.7 & \\
\hline Due to $M$. Carr (\%) & 1.6 & & 1.6 & & 1.6 & \\
\hline $\begin{array}{l}\text { Due to } S \text { pneumonia } \\
(\%)\end{array}$ & 30 & & 20 & & 20 & \\
\hline \multicolumn{7}{|l|}{ Direct medical costs } \\
\hline \multicolumn{7}{|l|}{ Vaccine cost per dose } \\
\hline PCV10 & $\$ 12.85$ & & $€ 44.00$ & & $€ 57.13$ & \\
\hline PCV13 & $\$ 14.75$ & & $€ 58.41$ & & $€ 68.56$ & \\
\hline
\end{tabular}


Table 1 continued

\begin{tabular}{|c|c|c|c|c|c|c|}
\hline Input & Colombia* & & Finland & & The Ne & \\
\hline $\begin{array}{l}\text { Administration cost } \\
\text { (per dose) }\end{array}$ & $\$ 1.00$ & & $€ 5.00$ & & $€ 10.63$ & \\
\hline $\begin{array}{l}\text { Pneumococcal } \\
\text { bacteremia (per case) }\end{array}$ & $\$ 5879$ & $\$ 5897$ & $€ 2065$ & $€ 7095$ & $€ 5572$ & $€ 5928$ \\
\hline $\begin{array}{l}\text { Pneumococcal } \\
\text { meningitis (per case) }\end{array}$ & $\$ 8321$ & $\$ 6026$ & $€ 22,949$ & $€ 22,387$ & $€ 10,162$ & $€ 17,653$ \\
\hline $\begin{array}{l}\text { Pneumonia inpatient } \\
\text { (per case) }\end{array}$ & $\$ 1330$ & $\$ 1876$ & $€ 3605$ & $€ 6000$ & $€ 2759$ & $€ 6112$ \\
\hline $\begin{array}{l}\text { Pneumonia outpatient } \\
\text { (per case) }\end{array}$ & - & - & $€ 187$ & $€ 187$ & $€ 514$ & $€ 857$ \\
\hline $\begin{array}{l}\text { Simple acute otitis } \\
\text { media (per case) }\end{array}$ & $\$ 29$ & & $€ 103$ & & $€ 20$ & \\
\hline
\end{tabular}

PCV10 10-valent pneumococcal conjugate vaccine, PCV13 13-valent pneumococcal conjugate vaccine, $A O M$ acute otitis media

${ }^{*}$ Costs for Colombia in US dollars

covered serotypes $(27 \%)$ caused the majority of residual disease. For individuals $\geq 65$ years of age, non-covered serotypes comprised the largest proportion of remaining disease (37\%) (Fig. 1). The RIPS database also informed the proportion of IPD that is meningitis and the current incidence of all-cause $\mathrm{OM}$ and hospitalized pneumonia. S. pneumoniae was assumed to cause $20 \%$ of pneumonia and $30 \%$ of OM [35]. Case fatality rates for pneumonia and IPD were derived from the literature for children $\leq 17$ [36] and adults $\geq 18$ years [37].

\section{Finland}

Finland introduced PCV10 as part of the FinIP clinical trial in 2009 followed by a full national immunization program in a $2+1$ schedule in 2010 (Table 1). The incidence of age- and serotype-specific IPD from 2004 to 2016 was derived from the National Institute for Health and Welfare pneumococcal surveillance data set [38]. At the year of potential switch, 14.4 cases of IPD per 100,000 remained, of which serotype $19 \mathrm{~A}$ and non-covered serotypes comprised $81 \%$ of the remaining disease in children $<2$ years of age and non-covered serotypes comprised $47 \%$ of remaining disease in adults $>65$ years old
(Fig. 1). The current incidence of all-cause OM in Finland was estimated based on adjusting the pre-PCV10 incidence derived from the literature [39] by an assumed PCV10 vaccine efficacy rate of $12 \%$ [40], which was assumed for all children $<5$ years because of high vaccine uptake in Finland. The incidence of hospital-diagnosed pneumonia was derived from the published literature for individuals $<5$ years old [41]. There were no published data on the incidence of hospitalized pneumonia in $>5$ year olds; therefore, we estimated the incidence in $>5$ year olds based on the ratio of pneumonia episodes in under 5 to $>5$ year olds in The Netherlands, a country similar to Finland with documented incidence of hospitalized pneumonia across all ages $[42,43]$. As $60 \%$ of pneumonia cases are hospitalized in Finland, the incidence of outpatient pneumonia was estimated based on the ratio of inpatient to outpatient cases [44]. We assumed that $20 \%$ of remaining all-cause pneumonia and OM cases in Finland are pneumococcal. Case fatality rates for IPD and pneumonia were obtained from the literature and consistent with estimates in economic analyses from the National Institute for Health and Welfare, Finland [45]. 

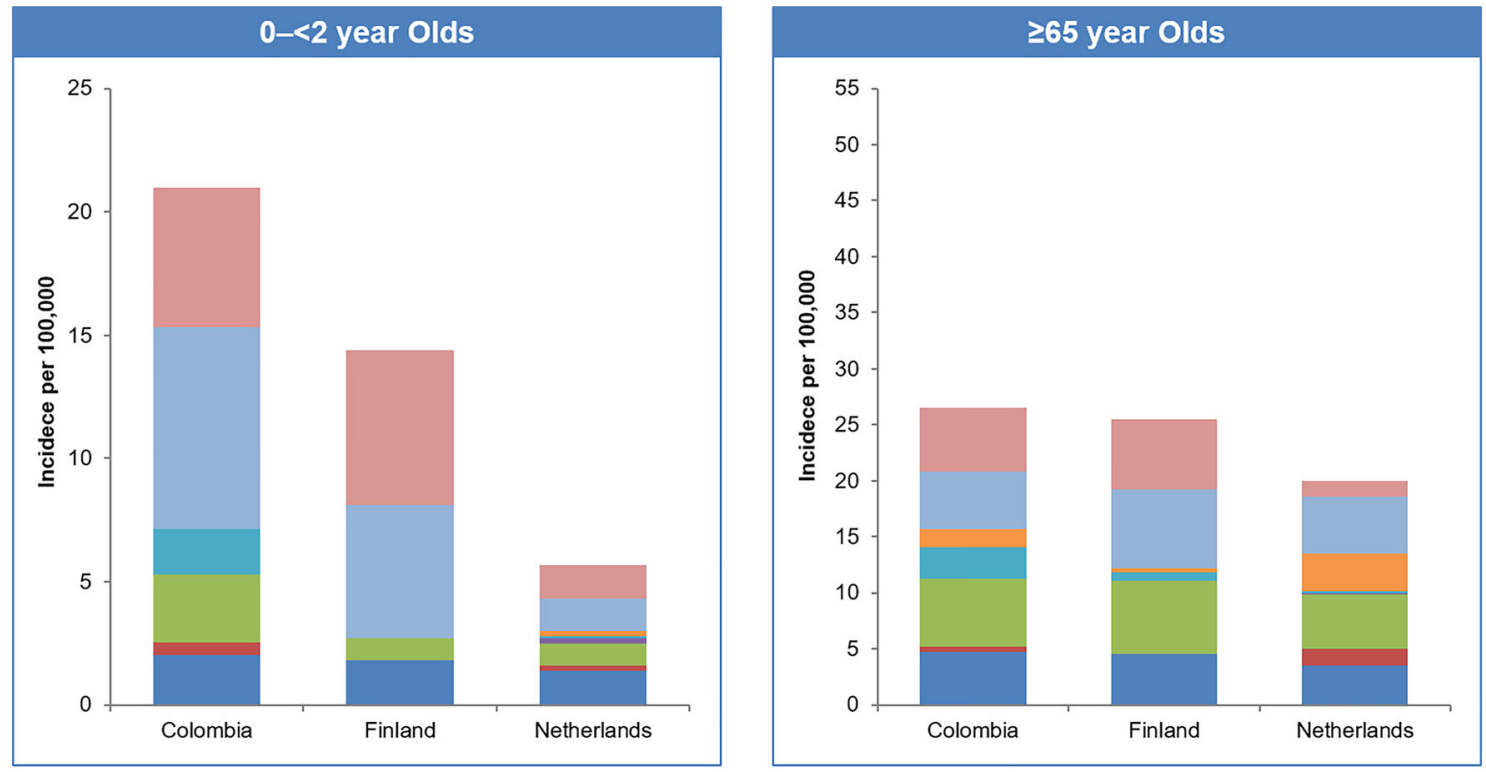

$\square$ PCV7 Serotypes $\square 1 \square 3 \square 5 \square 6$ A $\square$ 7F 19A $\square$ Non PCV13-type

Fig. 1 Baseline serotype distribution at year of potential switch. Blue: PCV7 Serotype, Red: 1, Green: 3, Purple: 5, Teal: 6A, Orange: 7F, Light blue: 19A, Pink: Non PCV13-type

\section{The Netherlands}

The Netherlands introduced PCV7 in 2006 followed by PCV10 in 2011, both programs in a $3+1$ schedule. Then, in 2013, the PCV10 schedule was reduced to $2+1$ (Table 1 ). The incidence of age- and serotype-specific IPD was obtained from the national surveillance system and National Institute for Public Health and the Environment [46] and adjusted to represent the entire Dutch population. At the year of potential switch, the incidence of IPD was 5.7 cases per 100,000 among children $<2$ years of age, with residual disease similarly distributed among serotypes 19A (23\%), non-covered serotypes $(25 \%)$, PCV7 serotypes $(25 \%)$, and serotype $3(15 \%)$ in children $<2$ years old, and non-covered serotypes comprised $64 \%$ of the remaining disease in adults $>65$ years old (Fig. 1). The pre-PCV10 incidence of all-cause OM was obtained from 2004-2011 from the Netherlands Information Network of General Practice and adjusted to post-PCV10 incidence based on an assumed PCV10 vaccine efficacy rate of $12 \%$, estimated from a double-blind randomized clinical trial on the effectiveness of PCV10 against AOM based on a $2+1$ schedule in Finland [40]. The incidence of hospitalized pneumonia per 10,000 hospitalizations in The Netherlands was obtained from the literature [42] and adjusted using Eurostat hospitalization data [43] to estimate the incidence of hospitalized pneumonia per total population. Nonhospitalized pneumonia was calculated using data from the National Institute for Public Health and the Environment [47] and adjusted using an estimate from the literature of the percent of reported outpatient pneumonia confirmed by x-ray [48]. Similarly to Finland, we assumed that $20 \%$ of all-cause pneumonia and $\mathrm{OM}$ in The Netherlands was pneumococcal. Case fatality rates were obtained from the literature for IPD and pneumonia for individuals $\geq 18$ years old [49] and for IPD [50] and pneumonia [51] among individuals $<18$ years.

\section{Economic Inputs}

\section{Colombia}

Direct medical costs associated with IPD, pneumonia and OM in Colombia were sourced from a previously published cost-effectiveness 
model and adjusted to 2016 values [52] (Table 1). The costs of PCV10 and PCV13 used in the analysis were the most recently available Pan American Health Association (PAHO) procurement prices.

\section{Finland}

Direct costs were calculated based on estimates from the National Institute for Health and Welfare and Department of Public Health [39] (Table 1). PCV10 and PCV13 were assumed based on wholesale prices.

\section{The Netherlands}

Direct medical costs were obtained from literature on pneumonia [53], IPD and OM [54] and adjusted to 2016 values (Table 1). PCV10 and PCV13 costs were estimated based on official Netherlands drug prices.

\section{Utilities}

For all three countries, utility decrements were applied for each occurrence of disease relative to an age-specific baseline utility weight for individuals who did not experience a case of disease. Annual decrements of 0.0070 and 0.0232 were assumed for bacteremia and meningitis [55], respectively, and decrements of 0.0050, 0.0040, and 0.0060 were assumed for OM, inpatient pneumonia, and outpatient pneumonia $[56,57]$. Sequelae such as neurologic impairment and hearing loss following a case of meningitis were assumed to occur with a probability of $7 \%$ and $13 \%$ in Colombia $[58,59]$ and $16 \%$ and $12 \%$ in Finland, respectively, and carried a lifetime QALY decrement of 0.40 and $0.20[57,60]$. With limited data in The Netherlands, we conservatively assumed no disease sequelae, which underestimates the true value of the program.

\section{Analysis}

In the base case analyses, cases of disease, deaths, and associated costs and QALYs were estimated over a 5-year time horizon assuming PCV10 was maintained in the NIP compared with a scenario where PCV10 was replaced with
PCV13. We assumed indirect effects (i.e., effects in those $>5$ years who are unvaccinated) for invasive disease and hospitalized pneumonia for both vaccines based on observed historical trends in non-vaccinated cohorts and included the additional impact of PCV13 only on NTHi and M. catarrhalis OM. An incremental cost-effectiveness ratio (ICER) was then calculated to estimate the cost-effectiveness of changing vaccination strategies. Costs and outcomes were discounted at a rate of 3.5\% for Colombia, 3\% for Finland and at $4.0 \%$ for costs and $1.5 \%$ for outcomes in The Netherlands [61]. Results are presented from a payer perspective. Baseline utilities for each country were sourced from published literature $[62,63]$.

A number of scenario and sensitivity analyses were undertaken to validate the robustness of results. Scenarios were run varying the time horizon (10 years), excluding indirect effects due to pneumonia, and the impact of both vaccines on OM due to NTHi and M. catarrhalis. For each country, additional scenarios were evaluated using serotype trends from the US, which implemented PCV13 in a $3+1$ schedule. Given the natural variation in vaccine implementation and uptake, these scenarios present potential serotype trajectories under different vaccine pressures.

We also tested the robustness of specific parameters in a one-way sensitivity analysis. Sensitivity analyses were undertaken on factors that may impact differentiation between vaccines. Individual parameters and assumptions varied based on 95\% confidence intervals (CIs) or $\pm 20 \%$ when neither CIs nor plausible ranges were available. A probabilistic sensitivity analysis was also performed (second-order Monte Carlo simulations). The proportion of IPD that is meningitis, vaccination rate, percentage of all-cause $\mathrm{OM}$ that is pneumococcal OM, percentage of all-cause pneumonia that is pneumococcal, utilities, and disease-specific mortality were drawn from beta distributions. Limits on forecasted incidence, time to disease reemergence, direct costs, vaccine acquisition costs, vaccine administration costs, myringotomy procedure cost, lost productivity, and number of general deaths were drawn from 
gamma distributions; 10,000 random draws were captured.

\section{RESULTS}

Results are first presented for the epidemiologic analysis and are for children $<2$ years old and those $>65$ years old as these age groups are most susceptible to pneumococcal disease and form the largest proportion of the total burden.

\section{Epidemiologic Model Results}

In Colombia, continued use of PCV10 over the next 5 years (2016-2021) was estimated to cause a $40.3 \%$ increase in serotypes 3, 6A, and 19A (Fig. 3), leading to an additional 17.9 cases per 100,000 of IPD due to these serotypes in 0 2 year olds (Fig. 2). In contrast, a switch to PCV13 was estimated to reduce PCV13-type IPD to 8.6 cases per 100,000 over the same 5 -year period in 0-2 year olds. Thus, PCV13 was estimated to reduce total IPD by $37.6 \%$ compared with PCV10 vaccination (Fig. 3), despite greater estimated serotype replacement of non-PCV13type disease with PCV13. A comparable trend was suggested in the $\geq 65$-year age group due to the indirect protection provided by a pediatric vaccination. Total estimated disease in adults $\geq 65$ years of age was reduced by $32 \%$ with PCV13 vaccination relative to PCV10.

In Finland, the overall impact of switching from PCV10 to PCV13 was similar to what was observed in Colombia for children $<2$ and adults $\geq 65$ years old. However, the serotypes driving the incremental IPD reductions in Finland differed from Colombia because of divergent serotype distributions at the year of vaccine switch (Fig. 1). After 5 years of continued use of PCV10, disease caused by serotypes 3 and 19A was estimated to increase by $52 \%$ to 9.5 cases per 100,000 in 0-2 year olds, while a switch to PCV13 would result in a $67 \%$ incremental reduction in these serotypes, leading to 2.3 cases per 100,000 over 5 years (Figs. 2 and 3). Similarly to Colombia, non-vaccine-type serotype replacement occurred in both PCV10 and PCV13 estimations,

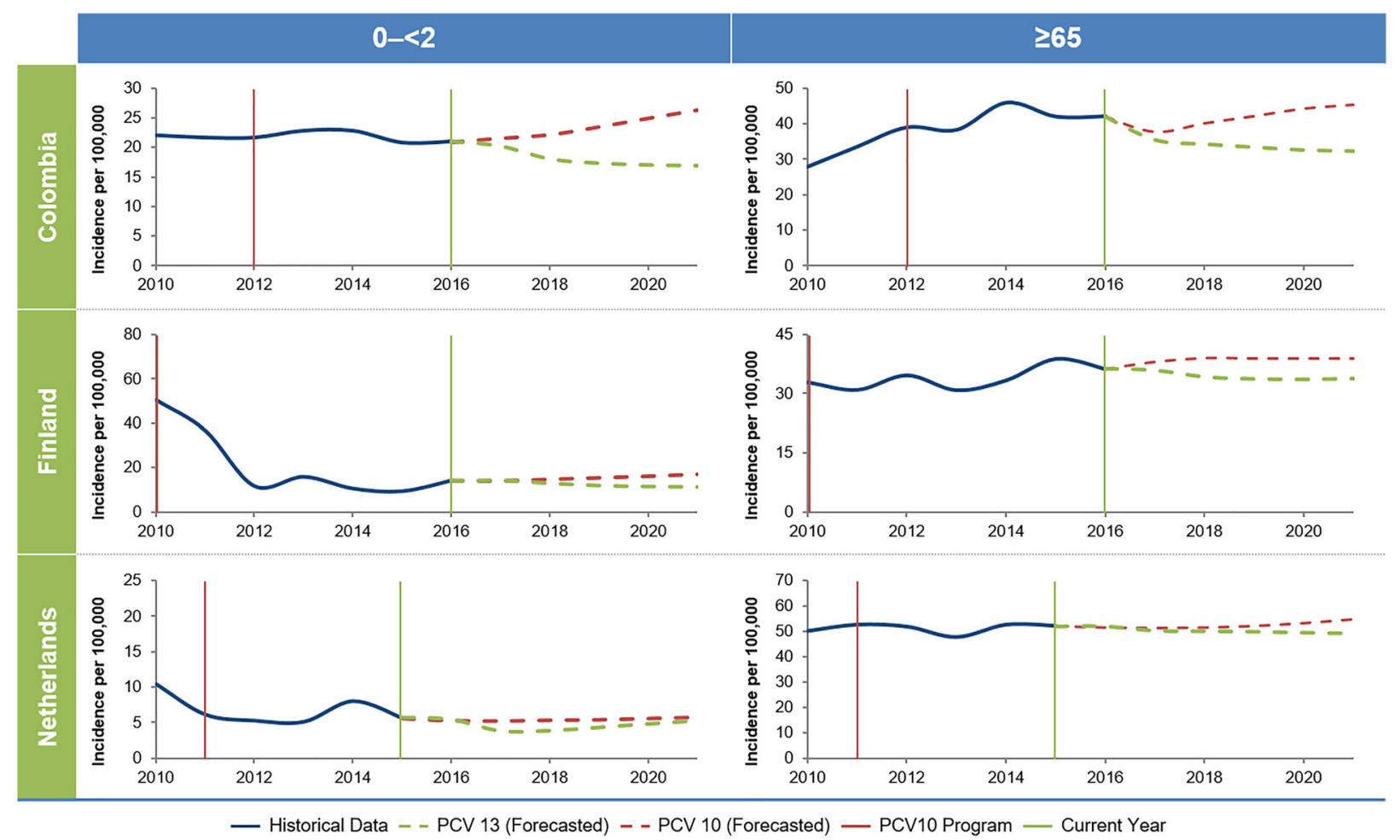

Fig. 2 Observed historical and forecasted overall IPD trend lines for Colombia, Finland, and The Netherlands with UK PCV13 trends 

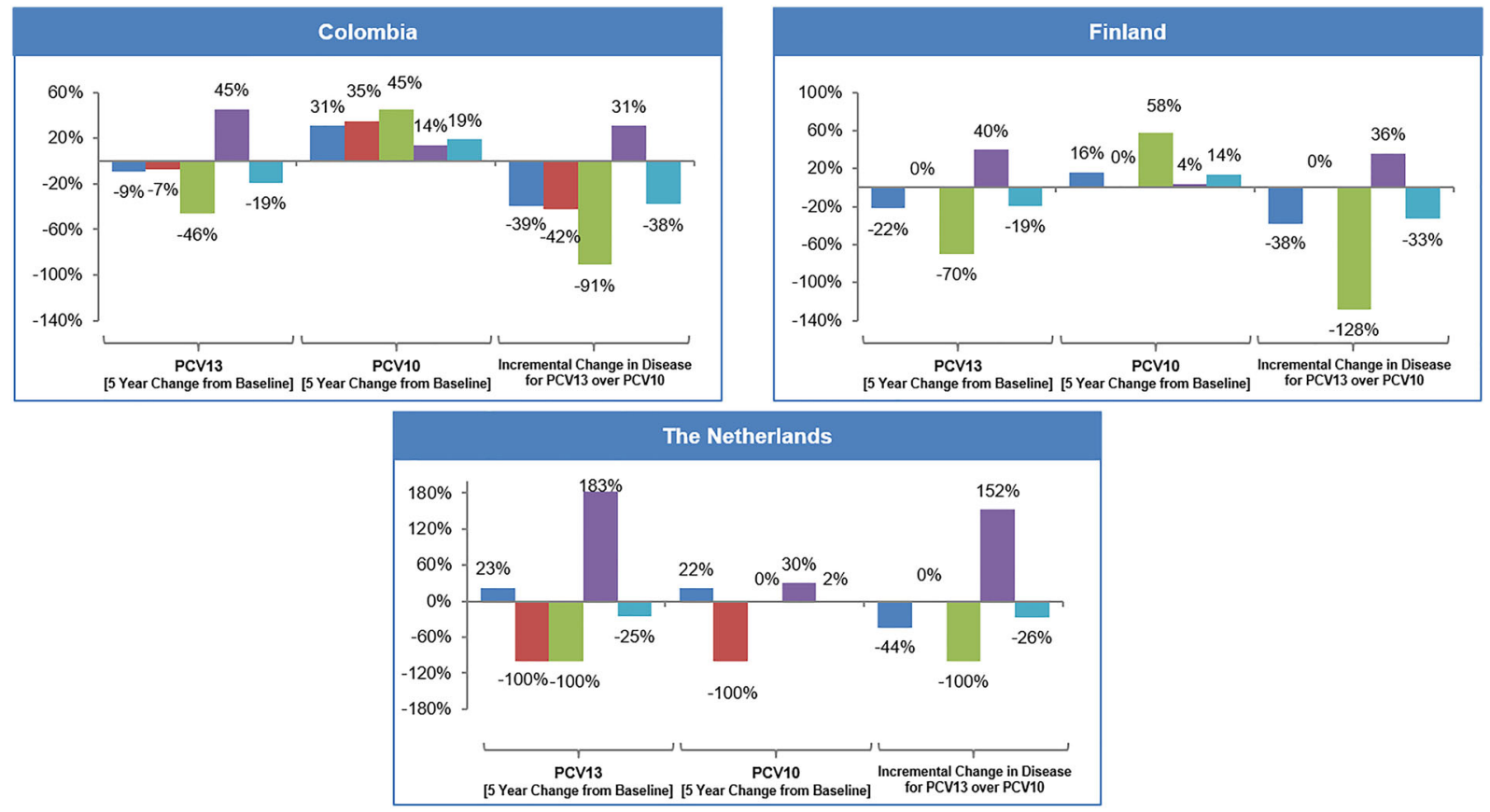

$3 \square$ 6A $\square$ 19A $\square$ Non-PCV13 Type $\square$ Total

Fig. 3 The percent change in IPD serotypes from the baseline serotype distribution at the year of switch to 5 years postPCV10 and post-PCV13, using a UK baseline, for ages $0-2$

but the overall reduction in disease was greater for PCV13 than PCV10. In 0-2 year olds, PCV13 vaccination was estimated to reduce total IPD to 11.4 cases per 100,000 . Adults $\geq 65$ years old would also benefit from a pediatric switch to PCV13 after 5 years with an estimated 15\% incremental reduction in IPD compared with PCV10, mainly because of reductions in disease caused by serotypes $3,6 \mathrm{~A}$, and $19 \mathrm{~A}$.

In The Netherlands, over 5 years, continued PCV10 vaccination was estimated to result in a mild increase in levels of IPD in 0-2 year olds, but a switch to PCV13 was estimated to reduce total disease by an incremental $26 \%$, mainly because of serotypes 3 and 19A (Figs. 2 and 3). Non-PCV13type serotype replacement was greater in the PCV13 estimation with an incremental increase of $152 \%$ over PCV10. In contrast, in adults $\geq 65$ years of age, non-covered serotypes were estimated to increase by $14.4 \%$ for PCV10 and by only $12.9 \%$ for PCV13, leading to a greater incremental benefit of PCV13 over PCV10.

\section{Base Case Cost-Effectiveness Results}

In all three countries, switching from PCV10 to PCV13 would avoid a significant number of cases, deaths, and costs after 5 years. In Colombia, a switch in vaccination program from PCV10 to PCV13 would avoid an incremental 156,082 cases of IPD, pneumonia, and OM and 3624 deaths due to pneumonia and IPD (Table 2). The additional cases prevented with PCV13 would save 6406 QALYs. Beyond the clinical benefit, a PCV13 program would save a total of $\$ 59.8$ million over 5 years and be cost-saving compared with maintaining PCV10. In Finland, a switch to PCV13 would avoid 644 cases of IPD, 963 cases of pneumonia, nearly 115,000 cases of OM, and 214 deaths. A PCV13 program in Finland was estimated to save 1003 QALYs and $€ 28.5 \mathrm{M}$ over 5 years. In The Netherlands, a switch from PCV10 to PCV13 would avoid an incremental 53,991 cases of IPD, pneumonia, and OM and 169 deaths due to pneumonia and IPD, resulting in 628 QALYs saved. Beyond the clinical benefit, a 
Table 2 Incremental cases, deaths, and costs under a PCV13 versus PCV10 vaccination program over a 5-year time horizon

\begin{tabular}{|c|c|c|c|}
\hline & $\begin{array}{l}\text { Colombia* } \\
\text { Incremental }\end{array}$ & $\begin{array}{l}\text { Finland } \\
\text { Incremental }\end{array}$ & $\begin{array}{l}\text { The Netherlands } \\
\text { Incremental }\end{array}$ \\
\hline \multicolumn{4}{|l|}{ Morbidity avoided } \\
\hline IPD & 5206 & 644 & 450 \\
\hline Acute otitis media & 114,160 & 114,858 & 50,651 \\
\hline Hospitalized pneumonia & 36,716 & 759 & 818 \\
\hline Non-hospitalized pneumonia & - & 204 & 2072 \\
\hline Total cases avoided & 156,082 & 116,465 & 53,991 \\
\hline \multicolumn{4}{|l|}{ Mortality avoided } \\
\hline IPD & 1729 & 91 & 117 \\
\hline Pneumonia & 1895 & 123 & 52 \\
\hline \multicolumn{4}{|l|}{ Outcomes } \\
\hline Life years & 7011 & 413 & 260 \\
\hline QALYs & 6406 & 1003 & 628 \\
\hline \multicolumn{4}{|l|}{ Direct medical cost } \\
\hline Vaccination program cost & $\$ 20,439,100$ & $€ 13,429,808$ & $€ 25,466,659$ \\
\hline IPD & $-\$ 30,937,116$ & $-€ 5,711,294$ & $-€ 2,627,723$ \\
\hline $\mathrm{AOM}$ & $-\$ 2,930,124$ & $-€ 32,901,343$ & $-€ 885,025$ \\
\hline Pneumonia & $-\$ 46,407,970$ & $-€ 3,338,335$ & $-€ 4,208,818$ \\
\hline Net cost, direct medical & $-\$ 59,836,109$ & $-€ 28,521,153$ & $€ 17,745,594$ \\
\hline \multicolumn{4}{|l|}{ Incremental cost-effectiveness } \\
\hline Cost per life year & PCV13 dominant & PCV13 dominant & $€ 68,142$ \\
\hline Cost per QALY & PCV13 dominant & PCV13 dominant & $€ 28,260$ \\
\hline
\end{tabular}

${ }^{*}$ Costs for Colombia in US dollars

PCV13 program would be highly cost-effective based on a $1 \times$ GDP per capita threshold at $€ 34,054$ per QALY.

\section{Scenario Analyses}

In Colombia, PCV13 remained the dominant program over PCV10 in all six one-way scenarios (Table 3) with cost-savings ranging from a $\$ 34 \mathrm{M}$, assuming no indirect impact of PCVs on pneumonia, to $\$ 197$ million based on a 10 -year time horizon. In Finland, PCV13 remained the dominant program, both over a 10-year time horizon and after excluding indirect effects on pneumonia. When the impact on NTHi was removed for both PCVs, PCV13 was no longer cost-saving, likely because of the high number of $\mathrm{OM}$ cases in Finland, but continued to be highly cost-effective. In The Netherlands, PCV13 remained highly cost-effective in oneway scenarios.

We also ran a scenario using US trend lines $(3+1$ schedule) for PCV13 (Supplemental Fig. 1, Table 3). The results for individual serotypes were similar to the main analysis using 


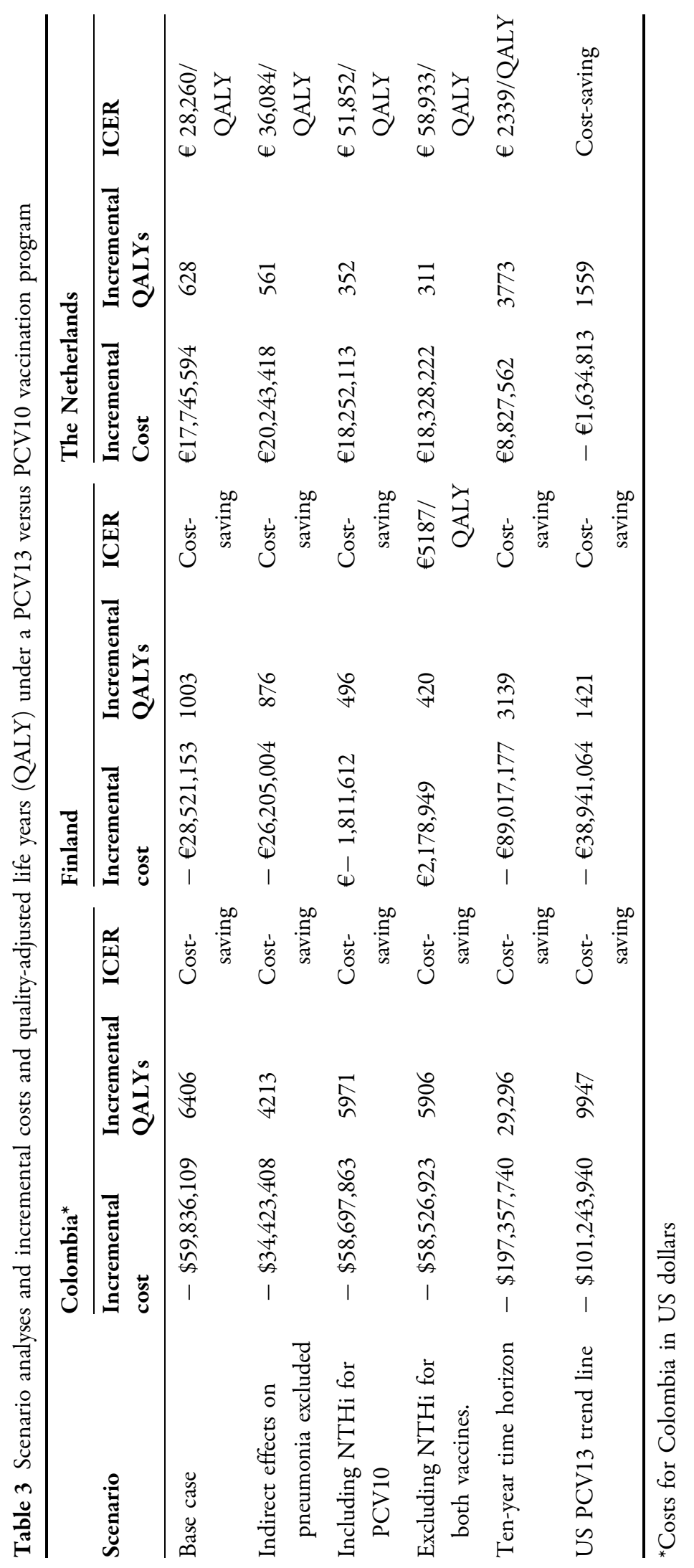


UK trend lines $(2+1$ schedule), but differed for non-PCV13-type serotypes, which may be explained by the historically lower non-PCV13type replacement seen in the US. When the UK trends were applied to all countries, there was an incremental increase in non-PCV13-type disease for PCV13 over PCV10. In contrast, when the US trends were applied there was less non-PCV13-type replacement for PCV13 relative to PCV10 for those $0-2$ and $\geq 65$ year olds, respectively, in Colombia $(-15.8 \%,-11 \%)$, Finland $(-5.7 \%,-10 \%)$, and The Netherlands $(-36.4 \%,-17.4 \%)$ (Supplemental Table 2). The additional decrease in disease when using US trend lines for PCV13 resulted in a greater incremental savings for PCV13 over PCV10 in Colombia and Finland, and the program in The Netherlands moved from highly cost-effective to cost-saving (Table 3).

The one-way sensitivity analysis (Supplemental Fig. 2) demonstrated that a PCV13based program remained cost-effective in The Netherlands and cost saving in Finland and Colombia over a 5-year horizon as parameters changed within their plausible range. The probabilistic sensitivity analysis showed that a PCV13-based program remained cost-saving in $100 \%$ of the simulations in Colombia and Finland, and a switch to PCV13 in The Netherlands was cost-effective at $<€ 60,000$ per QALY in 90\% of simulations (Supplemental Fig. 3).

\section{DISCUSSION}

Our analysis employs a novel forecasting framework to predict the future serotype dynamics in the event of a policy shift to a higher-valent vaccine. In all three countries included in the analysis, expanding the vaccination programs' serotype coverage from PCV10 to PCV13 would be a cost-saving or highly cost-effective strategy, despite the additional acquisition cost of the higher-valent vaccine. Such a policy shift could result in 156,082 pneumococcal disease cases avoided in Colombia, 116,465 in Finland, and 53,991 in The Netherlands over a 5-year time horizon. Furthermore, estimated rates of total IPD were further reduced in children and adults, highlighting the additional public health impact of a higher-valent vaccine.

These findings are supported by previous cost-effectiveness analyses. In The Netherlands, a previous study compared PCV7, PCV10, and PCV13 vaccination strategies and reported PCV13 was cost-effective compared with either lower-valent strategy [64]. A similar finding was also reported in Colombia where PCV13 was estimated to be less costly and more effective compared with PCV10 [52, 65]. However, both of these analyses used efficacy parameters from the original PCV7, adjusted by local serotype coverage; this method may be limited as it does not incorporate the robust real-world effectiveness data for both PCV10 and PCV13.

Few studies have utilized real-world evidence amassed from PCV use over the past 18 years to model future disease trends. Instead, previous studies often estimate direct effects for each vaccine based on clinical trial efficacy data, adjusted by local PCV10 or PCV13 serotype coverage [64-67]. Alternatively, studies estimate the same efficacy for the common vaccine-type serotypes and assume PCV10 provides crossprotection for serotypes 6A and 19A [68-70], serotypes only contained in PCV13. However, these approaches are limited by outdated assumptions around serotype replacement and cross protection and create challenges when comparing across economic evaluations because of differences in the literature from which efficacy assumptions are drawn [71, 72]. In contrast, utilizing observed disease trends based on country experience with PCV10 or PCV13 provides a real-world foundation on which to estimate how disease dynamics may behave in the future and would facilitate a simpler comparison across economic evaluations.

A similar methodology to the current analysis was applied in a recent study by Thorrington et al. [27] in which the authors utilized realworld effectiveness to estimate the impact of replacing the current PCV10 program with PCV13 in The Netherlands, though this analysis only considered the impact on older adults. Despite this, their findings demonstrated that the largest health benefit may be achieved in a strategy also including a switch to an infant 
PCV13 program. Our study builds on this by estimating the impact across all ages. Furthermore, our findings are supported by other realworld examples of switching vaccination programs, such as in New Zealand. New Zealand utilized PCV7 in 2008 followed by PCV10 in 2011, after which reports indicated an increase in IPD caused by serotype 19A. Then, in 2014, New Zealand switched to PCV13 and within only 1 year, experienced a $75 \%$ decrease in the number of cases of 19A in children $<5$ years of age, resulting in an overall decrease in IPD with a switch from PCV10 to PCV13 [73]. As of 2017, New Zealand switched back to PCV10; thus, continued disease monitoring will be critical to inform our understanding of serotype 19A behavior and the time to re-emergence without direct vaccine pressure. However, recent evidence from Belgium suggests an increase in the number of IPD cases caused by 19A from 2 cases in 2016 to 21 cases in 2017, just 2 years after a switch from PCV13 to PCV10 [74]. As a result, in 2018, the Belgium Superior Health Council updated the recommendation for Paediatric Pneumococcal Infections to propose the 13-valent vaccine be adopted in programs because of the widest protection against severe infections conferred by this vaccine [75].

The incremental clinical impact of PCV13 over PCV10 is largely due to the additional protection against invasive serotypes $3,6 \mathrm{~A}$, and 19A, which were important drivers in serotype replacement after the implementation of lower valent vaccines and are only contained within PCV13. Although vaccination does not directly cause serotype replacement, it is hypothesized that space in the nasopharynx, once occupied by vaccine types, but now vacant due to reduced acquisition and transmission, is filled by opportunistic acquisition of non-vaccine serotypes [14]. Therefore, under PCV10 programs, invasive serotypes not contained within the vaccine may move to occupy nasopharyngeal space. This concept was observed in our results, based on surveillance data, in which we estimated increases in serotypes 3, 6A, and 19A, at varying levels in Colombia, Finland, and The Netherlands under a PCV10 program. One outlier to these observed differences was in The Netherlands, where less disease caused by serotype 19A existed at the year of potential switch compared with other PCV10 countries, which in turn resulted in less incremental impact of PCV13 over PCV10 on 19A disease. Despite individual country differences, maintaining coverage against invasive serotypes is critical to ensure continued pressure to reduce carriage and transmission, which combined with direct protection of vaccination further contributes to reduced disease, as clinical evidence has shown that reducing vaccine pressure will result in increased carriage [74] and disease $[76,77]$ within a short time period.

This study may be limited by the application of trend lines informed by past behavior of serotypes, which may over- or under-estimate future replacement disease because stochastic serotype dynamics are influenced by a number of factors. However, a strength of this approach is that any population-level changes due to external factors such as seasonal influenza would be captured in the individual serotype behavior and used to inform forecasted disease. In addition, any impact of PPSV23 (Pneu$\operatorname{movax}^{\mathrm{TM}}$, Merck), an adult vaccination introduced in 1983, would be inherently captured as well because of the time frame of serotype trends captured. We have attempted to minimize that uncertainty by investigating the impact of serotype replacement on different trend line estimations derived from different epidemiologic settings, demonstrating that both trends and the outcomes they predict are robust across analyses. When we applied UK trend lines $(2+1$ schedule) for PCV13, all countries experienced an incremental increase in non-PCV13-type disease for PCV13 over PCV10. Yet, when US ( $3+1$ schedule) PCV13 trend lines were applied in scenario analyses, the opposite outcome was observed with all countries experiencing an incremental decrease in non-PCV13-type disease for PCV13 over PCV10. The difference in findings may be explained by the high non-PCV13-type replacement observed in the UK under a $2+1$ schedule versus the lower non-PCV13-type replacement observed in the US under a $3+1$ schedule. This finding also highlights the variation in estimates based on the applied country trend lines. The analysis is subject to the 
available surveillance data, which may be limited by the quality of reporting. Specifically, the SIREVA database in Latin America is dependent on reporting by hospitals and microbiology laboratories.

This study is strengthened by the diversity in economic, geographical, and social conditions across countries. Colombia, Finland, and The Netherlands were selected to investigate serotype dynamics, given the variation in vaccine introduction and serotype distribution across countries. For example, Finland implemented a PCV10 program into a largely PCV-naïve population, whereas Colombia and The Netherlands previously utilized PCV7, both beginning in 2006. The epidemiology of pneumococcal disease is complex, and as previous studies often apply a similar vaccine efficacy from one country to another, this study takes a tailored approach by highlighting that the complex nature of historical PCV use (time, vaccine type, uptake, etc.) is an important component. Despite these differences in sero-epidemiology and PCV use, a large burden of the remaining disease in these countries is still vaccine preventable. This provides validity that the impact is not unique to one country but is a public health gap in the remaining countries. Another strength of the study was the use of historical trend lines to forecast IPD because trends inherently incorporate indirect effects for all groups. Many cost-effectiveness analyses rely on point estimates of vaccine efficacy to try to simulate a population effect. This methodology underestimates the value of indirect effects and the impact of serotype replacement [72].

\section{CONCLUSION}

In conclusion, this study applies a novel and intuitive approach to forecast the clinical and economic impact of different vaccination strategies. By relying on observed historical data, our estimates may better reflect real-world effectiveness of pneumococcal vaccines given their extended use. This methodology will be important as higher-valent vaccines are introduced into the market. The similar finding observed across all three countries highlights the importance of vaccination against invasive serotypes such $3,6 \mathrm{~A}$, and 19A provided by a higher-valent vaccine, despite differences in population characteristics and vaccine program introduction. In all three countries included in the analysis, switching vaccination programs from PCV10 to PCV13 would be a cost-saving or highly cost-effective strategy and would significantly improve public health by reducing pneumococcal disease rates to even lower levels, beyond what has been achieved with the current vaccination program.

\section{ACKNOWLEDGEMENTS}

We thank Dr. Arie van der Ende from the Netherlands Reference Centre for Bacterial Meningitis (NRLBM) for kindly providing IPD data included in the modeling for The Netherlands.

Funding. This project and the Rapid Service Fees were funded by Pfizer, Inc.

Authorship. All named authors meet the International Committee of Medical Journal Editors (ICMJE) criteria for authorship for this article, take responsibility for the integrity of the work as a whole, and have given their approval for this version to be published.

Author Contributions. All authors made substantial contributions to the conception and design of the study. Susana Marques, Juan Manuel Reyes, Victor A Prieto, Davy Reijnders, Mark H Rozenbaum, Juha Laine, and Heidi Ahman contributed to the acquisition and interpretation of data. Margaret Moffatt, Matt Wasserman, and Sarah Pugh made substantial contributions to data analysis and interpretation. The first draft of the manuscript was written by Sarah Pugh, with modifications by all authors. All authors read and approved the final manuscript.

Disclosures. Sarah Pugh, Matt Wasserman, Margaret Moffatt, Susana Marques, Juan Manuel Reyes, Victor A Prieto, Davy Reijnders, Mark H 
Rozenbaum, Juha Laine, Heidi Ahman, and Raymond Farkouh are employees of Pfizer.

Compliance with Ethics Guidelines. This article is based on previously conducted studies and does not contain any studies with human participants or animals performed by any of the authors. All datasets used in the analyses for Colombia and Finland were obtained from previously published sources or publicly available databases. Dr. Arie van der Ende from the Netherlands Reference Centre for Bacterial Meningitis (NRLBM) kindly provided IPD data for The Netherlands.

Data Availability. The datasets during and/ or analyzed during the current study are available from the corresponding author on reasonable request.

Open Access. This article is licensed under a Creative Commons Attribution-NonCommercial 4.0 International License, which permits any non-commercial use, sharing, adaptation, distribution and reproduction in any medium or format, as long as you give appropriate credit to the original author(s) and the source, provide a link to the Creative Commons licence, and indicate if changes were made. The images or other third party material in this article are included in the article's Creative Commons licence, unless indicated otherwise in a credit line to the material. If material is not included in the article's Creative Commons licence and your intended use is not permitted by statutory regulation or exceeds the permitted use, you will need to obtain permission directly from the copyright holder. To view a copy of this licence, visit http://creativecommons.org/licenses/by$\mathrm{nc} / 4.0 /$.

\section{REFERENCES}

1. Estimated Hib and pneumococcal deaths for children under 5 years of age, 2008 [Available from: http://www.who.int/immunization/monitoring surveillance/burden/estimates/Pneumo_hib/en/.
2. Ardanuy C, Tubau F, Pallares R, Calatayud L, Dominguez MA, Rolo D, et al. Epidemiology of invasive pneumococcal disease among adult patients in Barcelona before and after pediatric seven-valent pneumococcal conjugate vaccine introduction, 1997-2007. Clin Infect Dis. 2009;48(1):57-64.

3. Berman M, Dube E, Quach C. Exploring the acceptability of the available pneumococcal conjugate vaccines in Canadian health care professionals and immunization experts. Vaccine. 2017;35(25): 3326-32.

4. Bettinger JA, Scheifele DW, Kellner JD, Halperin SA, Vaudry W, Law B, et al. The effect of routine vaccination on invasive pneumococcal infections in Canadian children, Immunization Monitoring Program, Active 2000-2007. Vaccine. 2010;28(9): 2130-6.

5. Casado-Flores J, Rodrigo C, Aristegui J, Martinon JM, Fenoll A, Mendez C. Decline in pneumococcal meningitis in Spain after introduction of the heptavalent pneumococcal conjugate vaccine. Pediatr Infect Dis J. 2008;27(11):1020-2.

6. Pilishvili T, Lexau C, Farley MM, Hadler J, Harrison $\mathrm{LH}$, Bennett NM, et al. Sustained reductions in invasive pneumococcal disease in the era of conjugate vaccine. J Infect Dis. 2010;201(1):32-41.

7. Rodenburg GD, de Greeff SC, Jansen AG, de Melker HE, Schouls LM, Hak E, et al. Effects of pneumococcal conjugate vaccine 2 years after its introduction, the Netherlands. Emerg Infect Dis. 2010;16(5): 816-23.

8. Ruckinger $\mathrm{S}$, van der Linden $\mathrm{M}$, Reinert $\mathrm{RR}$, von Kries R, Burckhardt F, Siedler A. Reduction in the incidence of invasive pneumococcal disease after general vaccination with seven-valent pneumococcal conjugate vaccine in Germany. Vaccine. 2009;27(31):4136-41.

9. Vestrheim DF, Hoiby EA, Bergsaker MR, Ronning K, Aaberge IS, Caugant DA. Indirect effect of conjugate pneumococcal vaccination in a $2+1$ dose schedule. Vaccine. 2010;28(10):2214-21.

10. Foster D, Walker AS, Paul J, Griffiths D, Knox K, Peto TE, et al. Reduction in invasive pneumococcal disease following implementation of the conjugate vaccine in the Oxfordshire region, England. J Med Microbiol. 2011;60(Pt 1):91-7.

11. Messina AF, Katz-Gaynor K, Barton T, Ahmad N, Ghaffar F, Rasko D, et al. Impact of the pneumococcal conjugate vaccine on serotype distribution and antimicrobial resistance of invasive Streptococcus pneumoniae isolates in Dallas, TX, children 
from 1999 through 2005. Pediatr Infect Dis J. 2007;26(6):461-7.

12. Munoz-Almagro C, Jordan I, Gene A, Latorre C, Garcia-Garcia JJ, Pallares R. Emergence of invasive pneumococcal disease caused by nonvaccine serotypes in the era of seven-valent conjugate vaccine. Clin Infect Dis. 2008;46(2):174-82.

13. Perez-Trallero E, Marimon JM, Ercibengoa M, Vicente D, Perez-Yarza EG. Invasive Streptococcus pneumoniae infections in children and older adults in the north of Spain before and after the introduction of the heptavalent pneumococcal conjugate vaccine. Eur J Clin Microbiol Infect Dis. 2009;28(7): 731-8.

14. Weinberger DM, Malley R, Lipsitch M. Serotype replacement in disease after pneumococcal vaccination. Lancet. 2011;378(9807):1962-73.

15. Foster D, Knox K, Walker AS, Griffiths DT, Moore H, Haworth E, et al. Invasive pneumococcal disease: epidemiology in children and adults prior to implementation of the conjugate vaccine in the Oxfordshire region, England. J Med Microbiol. 2008;57(Pt 4):480-7.

16. Jokinen J, Rinta-Kokko H, Siira L, Palmu AA, Virtanen MJ, Nohynek $\mathrm{H}$, et al. Impact of ten-valent pneumococcal conjugate vaccination on invasive pneumococcal disease in Finnish children-a population-based study. PLoS One. 2015;10(3): e0120290.

17. Knol MJ, de Melker HE, Sanders EAM, van der Ende $A$, editors. Incidence of IPD in the Netherlands up to five years after introduction of PCV102016: National Institute for Public Health and the Environment.

18. Brandileone MC, Almeida SCG, Minamisava R, Andrade AL. Distribution of invasive Streptococcus pneumoniae serotypes before and 5 years after the introduction of ten-valent pneumococcal conjugate vaccine in Brazil. Vaccine. 2018;36(19): 2559-66.

19. RIVM Report. The National Immunisation Programme in the Netherlands. Surveillance and developments in 2016-2017. 2017.

20. Isturiz R, Sings HL, Hilton B, Arguedas A, Reinert RR, Jodar L. Streptococcus pneumoniae serotype 19A: worldwide epidemiology. Expert Rev Vaccines. 2017;16(10):1007-27.

21. Song JH. Advances in pneumococcal antibiotic resistance. Expert Rev Respir Med. 2013;7(5):491-8.

22. Domenech M, Damian D, Ardanuy C, Linares J, Fenoll A, Garcia E. Emerging, non-PCV13 serotypes
$11 \mathrm{~A}$ and 35B of Streptococcus pneumoniae show high potential for biofilm formation in vitro. PLoS ONE. 2015;10(4):e0125636.

23. Kawaguchiya M, Urushibara N, Aung MS, Morimoto S, Ito M, Kudo K, et al. Emerging non-PCV13 serotypes of noninvasive Streptococcus pneumoniae with macrolide resistance genes in northern Japan. New Microbes New Infect. 2016;9:66-72.

24. Su LH, Kuo AJ, Chia JH, Li HC, Wu TL, Feng Y, et al. Evolving pneumococcal serotypes and sequence types in relation to high antibiotic stress and conditional pneumococcal immunization. Sci Rep. 2015;5:15843.

25. Wilson M, Wasserman M, Earnshaw S, McDade C, Pugh S, Moffatt M, Sings H, Hilton B, Farkouh R. Predicting invasive pneumococcal disease incidence: a forecasting approach. International Symposium on Pneumococcal and Pneumococcal Diseases. 2018.

26. Wilson $M$, Wasserman $M$, Jadavi $T$, Postma $M$, Breton MC, Peloquin F, et al. Clinical and economic impact of a potential switch from 13-valent to 10 -valent pneumococcal conjugate infant vaccination in Canada. Infect Dis Ther. 2018.

27. Thorrington D, van Rossum L, Knol M, de Melker $\mathrm{H}$, Rumke H, Hak E, et al. Impact and cost-effectiveness of different vaccination strategies to reduce the burden of pneumococcal disease among elderly in the Netherlands. PLoS One. 2018;13(2): e0192640.

28. van Hoek AJ, Choi YH, Trotter C, Miller E, Jit M. The cost-effectiveness of a 13-valent pneumococcal conjugate vaccination for infants in England. Vaccine. 2012;30(50):7205-13.

29. Dagan R, Pelton S, Bakaletz L, Cohen R. Prevention of early episodes of otitis media by pneumococcal vaccines might reduce progression to complex disease. Lancet Infect Dis. 2016;16(4):480-92.

30. Tregnaghi MW, Saez-Llorens X, Lopez P, Abate H, Smith E, Posleman A, et al. Correction: efficacy of pneumococcal nontypable haemophilus influenzae protein $\mathrm{D}$ conjugate vaccine (PHiD-CV) in young Latin American children: a double-blind randomized controlled trial. PLoS Med. 2015;12(6): e1001850.

31. Ben-Shimol S, Givon-Lavi N, Leibovitz E, Raiz S, Greenberg D, Dagan R. Impact of widespread introduction of pneumococcal conjugate vaccines on pneumococcal and nonpneumococcal otitis media. Clin Infect Dis. 2016;63(5):611-8.

32. Macroeconomics and health: Investing in health for economic development. Report of the 
Commission on Macroeconomics and Health. Geneva: World Health Organization; 2001.

33. Ministry of Health Colombia. Individual registration of health services (RIPS) database. Available at: https://www.minsalud.gov.co/proteccionsocial/ Paginas/rips.aspx. Accessed July 3, 2017.

34. Sanabria O, Valderrama, C. Streptococcus pneumoniae distribución de los aislamientos invasores por año de vigilancia, departamento, grupos de edad, serotipos y sensibilidad antimicrobiana: Instituto Nacional de Salud. Grupo de Microbiología. Informe Nacional SIREVA II. Colombia 2006-2016. Available at: http://www.paho.org/hq/index.php? option $=$ com_content\&view $=$ article\&id $=5536 \% 3 \mathrm{~A} 2$ 011-sireva-ii\&catid=1591\%3Aabout\&Itemid=3966\& lang=es. Accessed March 20, 2018 [.

35. Taboada BLL, Castro AL, Caicedo VMP, Camargo $\mathrm{BCB}$, Roa BJH. Etiología de la neumonía adquirida en la comunidad en un hospital de cuarto nivel en Bogotá: estudio descriptivo de un registro institucional durante los años 2007 a 2012. Infection. 2015;19(1):10-7.

36. Constenla D, Gomez E, de la Hoz FP, O'Loughlin R, Sinha A, Valcnai JE, et al. The burden of pneumococcal disease and cost-effectiveness of a pneumococcal vaccine in Latin America and the Caribbean. Sabin Vaccine Inst. 2007;1:129.

37. Castañeda-Orjuela, Carlos, Nelson Alvis-Guzmán, and Fernando De la Hoz-Restrepo. "Impacto de la enfermedad por Streptococcus pneumoniae en población adulta mayor en Bogotá, Colombia, 2008. Revista de Salud Pública 2010;12:38-50.

38. National Institute for Health and Welfare. Incidence of invasive pneumococcal disease in Finland. 2016.

39. Salo H. Economic evaluations in adopting new vaccines in the Finnish national vaccination programme. 2017.

40. Vesikari T, Forsten A, Seppä I, Kaijalainen T, Puumalainen $\mathrm{T}$, Soininen A, et al. Effectiveness of the 10 -valent pneumococcal nontypeable haemophilus influenzae protein D-conjugated vaccine (PHiD-CV) against carriage and acute otitis media-a doubleblind randomized clinical trial in Finland. J Pediatr Infect Dis Soc. 2016;5(3):237-48.

41. Palmu AA, Rinta-Kokko H, Nohynek H, Nuorti JP, Kilpi TM, Jokinen J. Impact of ten-valent pneumococcal conjugate vaccine on pneumonia in Finnish children in a nation-wide population-based study. PLoS One. 2017;12(3):e0172690.

42. van Deursen AMM, Schurink-Van't Klooster TM, Man WH, van de Kassteele J, van Gageldonk-
Lafeber $A B$, Bruijning-Verhagen $P$, et al. Impact of infant pneumococcal conjugate vaccination on community acquired pneumonia hospitalization in all ages in the Netherlands. Vaccine. 2017;35(51): 7107-13.

43. Eurostat. Hospital discharges by diagnosis, in-patients, per 100000 inhabitants 2017 [Available from: http://appsso.eurostat.ec.europa.eu/nui/show. do?query=BOOKMARK_DS-052702_QID_-5CE5B1 62_UID_-3F171EB0\&layout $=S E X, L, X, 0 ; A G E, L, X, 1$; TIME,C,Y,0;GEO,L,Y,1;INDIC_HE,L,Z,0;UNIT,C,Z,1; ICD10,L,Z,2;INDICATORS, C,Z,3;\&zSelection=DS052702UNIT,P_HTHAB;DS-052702INDIC_HE,INPAT; DS-052702ICD10,A-T_Z;DS-052702INDICATORS, OBS_FLAG;\&rankName1=ICD10_1_2 - $1 \_2 \&$ rank Name2=INDIC-HE_1_2_-1_2\&rankName3=UNIT_ $1 \_2 \_-1 \_2 \&$ rankName4=INDICATORS_1_2_-1_2\&rank Name5=SEX_1_2_0_0\&rankName6=AGE_1_2_1 0\&rankName7=TIME_1_0_0_1\&rankName8=GEO_ $1 \_2 \_1 \_1 \&$ sortR=ASC_-1_FIRST $\& \mathrm{rStp}=\& \mathrm{CStp}=\& \mathrm{rDCh}=$ $\& \mathrm{cDCh}=\& \mathrm{rDM}=$ true\&cDM=true \&footnes=false \&empty=false\&wai=false\&time_mode=ROLLING \&time_most_recent $=$ false $\&$ lang $=\mathrm{EN} \& \mathrm{cfo}=\% 23 \%$ $23 \% 23 \% 2 \mathrm{C} \% 23 \% 23 \% 23 . \% 23 \% 23 \% 23$.

44. Koskela H. Keuhkokuumeen aiheuttama sairaalahoidon tarve nyt ja tulevaisuudessa. Suomen Lääkärilehti. 2013;18/2013, (vsk 68):1349-55.

45. Taloudellinen arviointi. 2015 [Available from: http://fi.opasnet.org/fi/Taloudellinen_arviointi.

46. Knol M, de Melker HE, Sanders EAM, van der Ende $\mathrm{A}$, editors. Incidence of IPD in the Netherlands up to five years after introduction of PCV102016: National Institute for Public Health and the Environment.

47. Volksgezondheidenzorg. Aantal nieuwe gevallen van longontsteking 2015 [Available from: https:// www.volksgezondheidenzorg.info/onderwerp/ infecties-van-de-onderste-luchtwegen/cijferscontext/huidige-situatie\#node-aantal-nieuwegevallen-van-longontsteking.

48. van Vugt SF, Verheij TJ, de Jong PA, Butler CC, Hood K, Coenen S, et al. Diagnosing pneumonia in patients with acute cough: clinical judgment compared to chest radiography. Eur Respir J. 2013;42(4): 1076-82.

49. Mangen MJ, Rozenbaum MH, Huijts SM, van Werkhoven $\mathrm{CH}$, Postma DF, Atwood M, et al. Cost-effectiveness of adult pneumococcal conjugate vaccination in the Netherlands. Eur Respir J. 2015;46(5):1407-16.

50. Wagenvoort GH, Sanders EA, Vlaminckx BJ, Elberse $\mathrm{KE}$, de Melker HE, van der Ende A, et al. Invasive pneumococcal disease: clinical outcomes and patient characteristics 2-6 years after introduction 
of seven-valent pneumococcal conjugate vaccine compared to the pre-vaccine period, the Netherlands. Vaccine. 2016;34(8):1077-85.

51. Melegaro A, Edmunds WJ, Pebody R, Miller E, George R. The current burden of pneumococcal disease in England and Wales. J Infect. 2006;52(1): 37-48.

52. Ordóñez JE, Orozco JJ. Cost-effectiveness analysis of the available pneumococcal conjugated vaccines for children under 5 years in Colombia. Cost Effect Resour Alloc. 2015;13(1):6.

53. Rozenbaum MH, Mangen MJ, Huijts SM, van der Werf TS, Postma MJ. Incidence, direct costs and duration of hospitalization of patients hospitalized with community acquired pneumonia: a nationwide retrospective claims database analysis. Vaccine. 2015;33(28):3193-9.

54. Rozenbaum MH, Sanders EA, van Hoek AJ, Jansen AG, van der Ende A, van den Dobbelsteen G, et al. Cost effectiveness of pneumococcal vaccination among Dutch infants: economic analysis of the seven valent pneumococcal conjugated vaccine and forecast for the ten valent and 13 valent vaccines. BMJ. 2010;340:c2509.

55. Bennett JE, Sumner W 2nd, Downs SM, Jaffe DM. Parents' utilities for outcomes of occult bacteremia. Arch Pediatr Adolesc Med. 2000;154(1):43-8.

56. Melegaro A, Edmunds WJ. Cost-effectiveness analysis of pneumococcal conjugate vaccination in England and Wales. Vaccine. 2004;22(31-32): 4203-14.

57. Cheng AK, Niparko JK. Cost-utility of the cochlear implant in adults: a meta-analysis. Arch Otolaryngol Head Neck Surg. 1999;125(11):1214-8.

58. McIntyre PB, Berkey CS, King SM, Schaad UB, Kilpi T, Kanra GY, et al. Dexamethasone as adjunctive therapy in bacterial meningitis. A meta-analysis of randomized clinical trials since 1988. JAMA. 1997;278(11):925-31.

59. Pomeroy SL, Holmes SJ, Dodge PR, Feigin RD. Seizures and other neurologic sequelae of bacterial meningitis in children. N Engl J Med. 1990;323(24): 1651-7.

60. Morrow A, De Wals P, Petit G, Guay M, Erickson LJ. The burden of pneumococcal disease in the Canadian population before routine use of the sevenvalent pneumococcal conjugate vaccine. Can J Infect Dis Med Microbiol. 2007;18(2):121-7.

61. Hakkaart-van Roijen L, van der Linden N, Bouwmans C, Kanters T, Tan SS. Institute for medical technology assessment Erasmus Universiteit
Rotterdam, [Available from: https://www.zorgin stituutnederland.nl/binaries/zinl/documenten/ publicatie/2016/02/29/richtlijn-voor-het-uitvoerenvan-economische-evaluaties-in-de-gezondheidszorg/ Richtlijn+voor+het+uitvoeren+van+economische+ evaluaties + in + de + gezondheidszorg $+\% 28$ verdiep ingsmodules\%29.pdf.

62. Mittmann N, Trakas K, Risebrough N, Liu BA. Utility scores for chronic conditions in a communitydwelling population. Pharmacoeconomics. 1999;15(4):369-76.

63. Stolk E, Krabbe P, Busschbach J, editor Using the internet to collect EQ-5D norm scores a valid alternative?. 24th Scientific Plenary Meeting of the EuroQol Group- Proceedings; 2009: EuroQol Group.

64. Strutton DR, Farkouh RA, Earnshaw SR, Hwang S, Theidel U, Kontodimas S, et al. Cost-effectiveness of 13-valent pneumococcal conjugate vaccine: Germany, Greece, and The Netherlands. J Infect. 2012;64(1):54-67.

65. Klok RM, Lindkvist RM, Ekelund M, Farkouh RA, Strutton DR. Cost-effectiveness of a 10- versus 13 -valent pneumococcal conjugate vaccine in Denmark and Sweden. Clin Ther. 2013;35(2): 119-34.

66. Kulpeng W, Leelahavarong P, Rattanavipapong W, Sornsrivichai V, Baggett HC, Meeyai A, et al. Costutility analysis of 10- and 13-valent pneumococcal conjugate vaccines: protection at what price in the Thai context? Vaccine. 2013;31(26):2839-47.

67. Kuhlmann A, von der Schulenburg JG. Modeling the cost-effectiveness of infant vaccination with pneumococcal conjugate vaccines in Germany. Eur J Health Econ. 2016.

68. Lara C, De Graeve D, Franco F. Cost-effectiveness analysis of pneumococcal and influenza vaccines administered to children less than 5 years of age in a low-income District of Bogota, Colombia. alue Health Reg Issues. 2018;17:21-31.

69. Shiragami M, Mizukami A, Leeuwenkamp O, Mrkvan T, Delgleize E, Kurono Y, et al. Cost-effectiveness evaluation of the ten-valent pneumococcal non-typeable haemophilus influenzae protein $\mathrm{D}$ conjugate vaccine and 13-valent pneumococcal vaccine in Japanese children. Infect Dis Ther. 2014.

70. Delgleize E, Leeuwenkamp O, Theodorou E, Van de Velde N. Cost-effectiveness analysis of routine pneumococcal vaccination in the UK: a comparison of the PHiD-CV vaccine and the PCV-13 vaccine using a Markov model. BMJ Open. 2016;6(11): e010776. 
71. Wu DB, Chaiyakunapruk N, Chong HY, Beutels P. Choosing between 7-, 10- and 13-valent pneumococcal conjugate vaccines in childhood: a review of economic evaluations (2006-2014). Vaccine. 2015;33(14):1633-58.

72. Wasserman M, Sings HL, Jones D, Pugh S, Moffatt M, Farkouh R. Review of vaccine effectiveness assumptions used in economic evaluations of infant pneumococcal conjugate vaccine. Expert Rev Vaccines. 2018;17(1):71-8.

73. Limited IoESaR. Invasive Pneumococcal Disease in New Zealand, 2015. ESR. 2017.

74. Desmet S, Verhaegen J, Van Ranst M, Peetermans W, Lagrou K. Switch in a childhood pneumococcal vaccination programme from PCV13 to PCV10: a defendable approach? Lancet Infect Dis. 2018.
75. Belgium Superior Health Council. Infant Pneumococcal Vaccination 2018 [Dec 2018]. Available from: https://www.health.belgium.be/en/node/ 34692.

76. Tagarro A, Benito A, Sanchez A, Aznar E, Otheo E, Sanz-Rosa D, et al. Bacteremic pneumonia before and after withdrawal of 13 -valent pneumococcal conjugate vaccine from a public vaccination program in Spain: a case-control study. J Pediatr. 2016;171(111-5):e1-3.

77. Picazo J, Ruiz-Contreras J, Mendez C, et al. Serotype distribution of invasive pneumococcal isolates among hospitalized children after systematic use of PCV7 in Madrid, Spain (HERACLES Study). ESPID 2008; Graz, Austria 2008. 